\title{
GEOLOCATION SUPPORT FOR WATER SUPPLY AND SEWERAGE PROJECTS IN AZERBAIJAN
}

\author{
M.H.Qocamanov ${ }^{1}$, Ch.Z.Gurbanov ${ }^{2}$ \\ ${ }^{1,2}$ Baku State University, Z.Khalilov Street, Baku, Azerbaijan, AZ1148 \\ mgodja@yandex.ru, chgurbanov@mail.ru
}

Commission IV, WG IV/4

KEY WORDS: Water supply, Sewerage system, GI, Programme support, Geodetic monitoring, Environment, Plan-height
positioning

\begin{abstract}
:
Drinking water supply and sewerage system designing and reconstruction projects are being extensively conducted in Azerbaijan Republic. During implementation of such projects, collecting large amount of information about the area and detailed investigations are crucial. Joint use of the aerospace monitoring and GIS play an essential role for the studies of the impact of environmental factors, development of the analytical information systems and others, while achieving the reliable performance of the existing and designed major water supply pipelines, as well as construction and exploitation of the technical installations. With our participation the GIS has been created in "Azersu" OJSC that includes systematic database of the drinking water supply and sewerage system, and rain water networks to carry out necessary geo information analysis. GIScreated based on "Microstation" platform and aerospace data.

Should be mentioned that, in the country, specifically in large cities (i.e. Baku, Ganja, Sumqait, etc.,) drinking water supply pipelines cross regions with different physico-geographical conditions, geo-morphological compositions and seismotectonics.Mains water supply lines in many accidents occur during the operation, it also creates problems with drinking water consumers. In some cases the damage is caused by large-scale accidents. Long-term experience gives reason to say that the elimination of the consequences of accidents is a major cost. Therefore, to avoid such events and to prevent their exploitation and geodetic monitoring system to improve the rules on key issues. Therefore, constant control of the plan-height positioning, geodetic measurements for the detailed examination of the dynamics, repetition of the geodetic measurements for certain time intervals, or in other words regular monitoring is very important. During geodetic monitoring using the GIS has special significance. Given that, collecting geodetic monitoring measurements of the main pipelines on the same coordinate system and processing these data on a single GIS system allows the implementation of overall assessment of plan-height state of major water supply pipeline network facilities and the study of the impact of water supply network on environment and alternatively, the impact of natural processes on major pipeline.
\end{abstract}

\section{INRTODUCTION}

According to the State Programs approved by Decrees of the President of the Republic of Azerbaijan, large-scale projects are being implemented in country in connection with the drinking water supply and sewerage system projecting and reconstruction. In recent years, the setbacks have occurred due to not providing the necessary technical services in the existing water supply and sewage systems, as well not allocation of investments in this sphere. The accidents occurred in existing water supply infrastructure created conditions for the drinking water losses and interruptions in the supply of drinking water. Therefore, project with reconstruction of water supply and sewerage systems are developed and this time cartographic, geodetic (plan, mapping, geodesy provision) data collection about the area is emphasized, first of all. It should be noted that for carrying out these kinds of works, it is important to get information on engineering-geologic, hydro-geological conditions. Otherwise, it is impossible to get a precise result on the availability of water in the potential sources of water resources. There is a need in the modern aerospace research methods, geodesy \& cartography and application of geographic data systems technologies for the successful implementation of such projects, for qualitative and effective conduction of works. At the same time after the completion of such projects the matters of organization of monitoring of their geospatial state are also very important during operation of established water supply and sewerage system.

\section{A DESCRIPTION OF OGUZ-GABALA-BAKU WATER PIPELINE SYSTEM}

Networks of wide main water supply pipelines are created in the country, especially for the supply of drinking water in the big cities (Baku, Ganja, Sumgait etc.). Let's comment their creation and operation features on the case of Oguz-Gabala-Baku water pipeline system.

Oguz-Gabala-Baku water pipeline system was designed for supply of drinking water from the northern mountains of Azerbaijan to the capital Baku city. Main line connects water reservoir in Oguz line with the pressure reducing chamber in Baku. The pipeline's length is $251 \mathrm{~km}$ and a diameter is $2 \mathrm{~m}$, which is manufactured of Glass fiber Reinforced Pipe (GRP) and Steel Pipes (SP).

The water pipeline starts from water reservoir in Oguz, with a capacity of $20000 \mathrm{~m}^{3}$. Here, the maximum water level altitude of source is 415 meters. Drinking water is transferred from water reservoir to first a pressure breaking chamber (PBC 1) located at $153,6 \mathrm{~km}$, then to the second pressure breaking chamber in $\mathrm{Baku}(\mathrm{PBC} 2)$. The water level in the first pressure reducer chamber is $288 \mathrm{~m}$, and $188 \mathrm{~m}$ in the second.

There are two tap chambers on the pipeline. One of theme is flow control valve (FCV), and the other is pressure control valve (PCV): both chambers have 4 plunger valves of 800-diameter with similar characteristics. The purpose of the flow and pressure control chambers is to regulate a flow through the pipeline. Flow 
control chamber is located $31.2 \mathrm{~km}$ from Oguz water reservoir chamber and pressure control chamber at the $158.4 \mathrm{~km}$ distance. Figure 1 shows the schematic description of the pipeline and figure 2 the schematic profile of area.

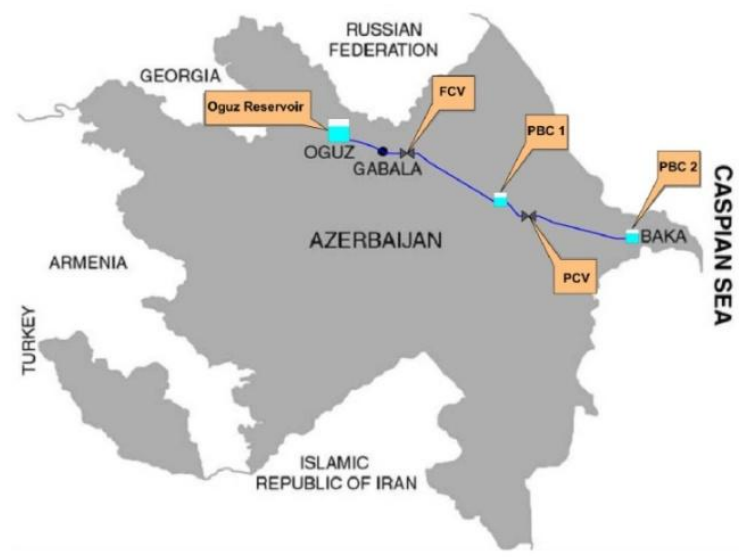

Figure 1. Schematic description of the Oguz-Gabala-Baku water pipeline system

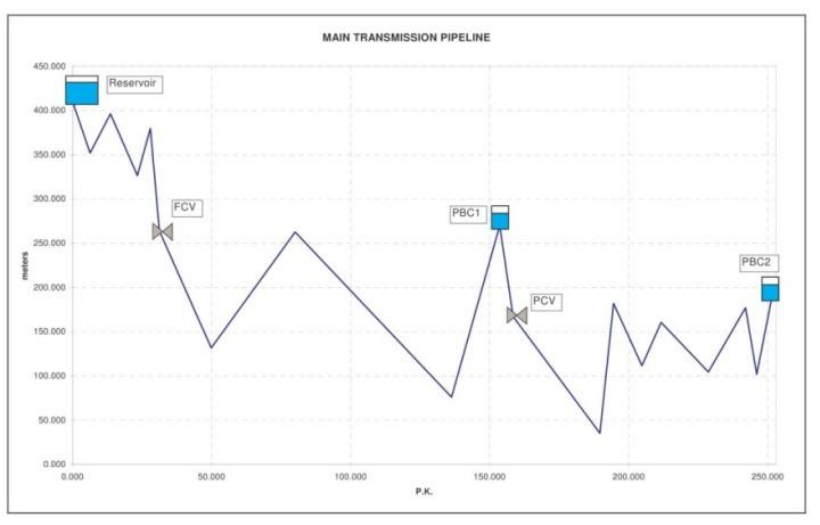

Figure 2. Oguz-Gabala-Baku pipeline site schematic profile

\section{THE PHYSICAL AND GEOGRAPHICAL CONDITIONS OF THE AREA OF PASSING OF OGUZ-GABALA-BAKU WATER PIPELINE}

As seen from Figure (1-4) the Oguz-Gabala-Baku water pipeline passes through the region with different physical-geographical conditions, geological - geomorphologic structure, seismictectonic activity (Gojamanov, 2014).

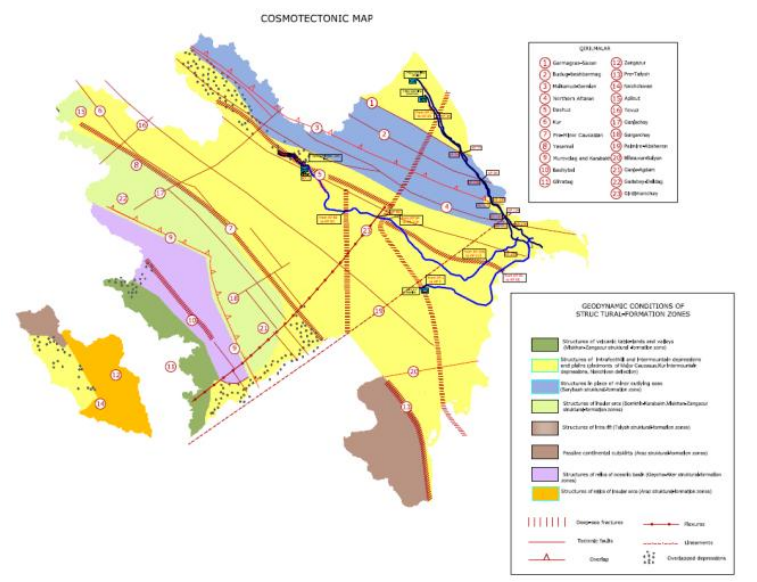

Figure 3. Physical-geographical conditions, geological geomorphologic structure in Azerbaijan

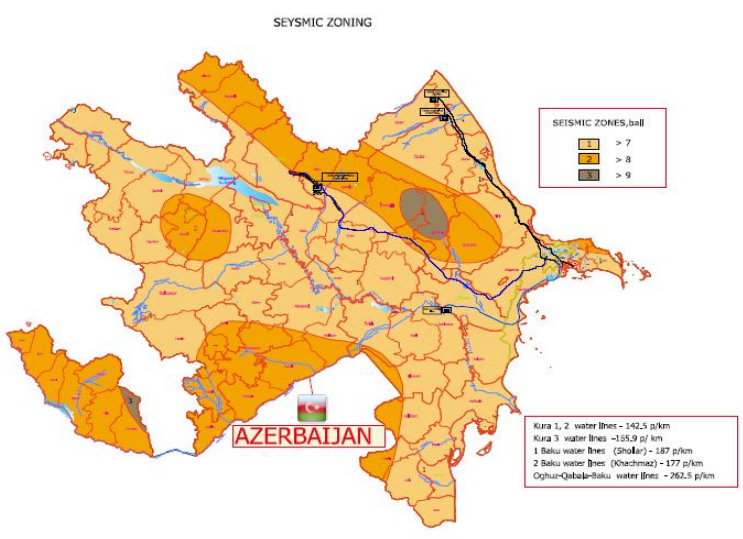

Figure 4. Seismic-tectonic activity in Azerbaijan

As seen from Figure (1-4) the Oguz-Gabala-Baku water pipeline passes through the region with different physical-geographical conditions, geological - geomorphologic structure, seismictectonic activity (Gojamanov, 2014).

During the operation of the water supply natural and technological system various types and sizes of disasters can occur and emergencies arise, the main reason of that is connected with interrelated influence of technological elements of the system and the natural environment. In many cases, this process takes place at background of a dynamic imbalance. This leads to the activation of dangerous natural and man-made processes. In turn, these processes affect the water supply plan-altitude conditions. As nature and technical systems are interrelated, the noted also affects environment, at result ecological environment, as well as socio-economic conditions deteriorate. Therefore, for the assessment of geo-ecological conditions of natural-technical system of main water pipelines, development of specific methods and techniques and on this basis the elimination or reduction of consequences of the accident, the necessity to develop appropriate technologies arises. This is the important and urgent evidence of conduction of monitoring in space-time size of the naturaltechnical system of main water pipes as a whole.

The peculiarity of the project is that in its implementation the SCADA (Supervisory Control and Data Acquisition) system is used (Figure 5). Note that the system applied for controlling of main water lines, water supply and sewerage systems from a unified center regulates online transfer of water from source to consumer. The volume of water in reservoirs by means of the system, working conditions of taps, the pressure available in reservoir exits and network, the reserve capacity of reservoirs are controlled automatically. At the same time, the geographical coordinates of the breakdown in the lines are recorded, promptly eliminating of the problem is provided. 


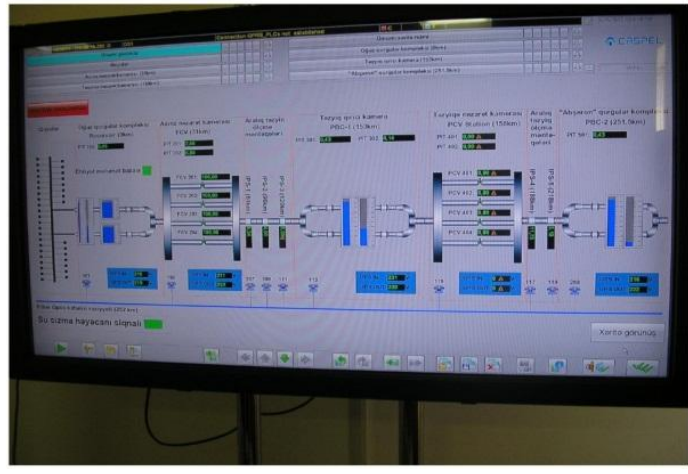

Figure 5. SCADA system main line

\section{AZERSU GIS}

The collection and analysis of necessary data for designing of drinking water supply and sewerage systems (geodetic, topographical, cartographic, geological, etc.) into a single information space, the relevant coordinate system of this information during the execution of the project and showing of these data in cartographic projections is impossible to imagine without use of geographic information in the modern world. During the implementation of such projects carried out in the engineering and geodetic, geological and topographical plans of the important documents. In addition, within the framework of project the fund and literature data within geologic - engineering exploration work in the projecting area are collected and analyzed, geologic exploration wells are drilled to study engineering and geological condition and physical-mechanical properties of geologic-engineering conditions and rocks, and laboratory experiments conducted. The GIS is an indispensable tool in collection, systemizing and analyzing of graphic and digital data at result of conducted studies.

"Azersu" OJSC widely uses geographic information systems (Aliyev, 2011) and (Gojamanov and Gurbanov, 2014) (Figure 6). So, geographic information system installed here keeps systematic data on drinking water supply and sewage, as well as storm water networks, and it creates a unique opportunity to conduct the necessary analysis of geographic information. One of the advantages of the created system is availability of its survey systems.

The software platform of built-system is "Microstation". One of the main advantages of this platform is that it is related to its Automated Design Systems (ADS). ADS system provides an optimum level development of the project, depending on the task of technical issues and based on initial data and data from other sources. However, the having specific dashboard related to geographic information systems makes it superb over other programs. It is possible here to conduct geo-reference operations with coordinate system and definition of cartographic projection likewise in software specific to other geo-information system. Moreover, this program has the ability to refer directly to the Google Earth platform, which in absence of the aerospace images enables to use research data with remote sensing with high identification capability of Digital Globe Company.
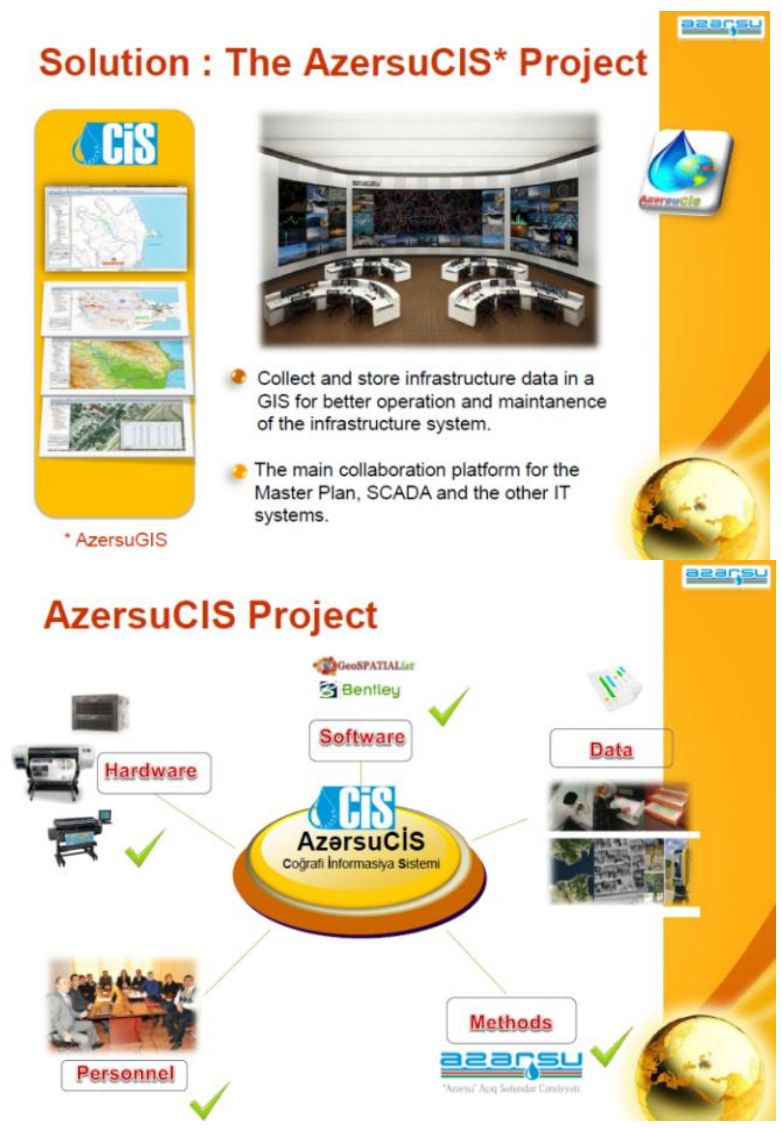

Figure 6. AzersuGIS Project

Usually, one of the main problems encountered in the geoinformation analysis is related to the establishment of relations between databases with ADS platforms. Relations should be conducted both on the space, but also on the attributive data. In AzersuGIS system these issues have been resolved by a software module of "Geospatialist". Combination of object and its attributive data ensures more complete geo-information analysis. During designing of water supply pipelines, the construction and operation it is very important to study the interaction between its various elements. In addition, geo-ecological assessment of the piping system should be carried out regularly. For this purpose observation-measuring information on the geological state of pipelines is to be collected. Therefore, for assessment of geological state of natural-technical system of water supply main pipelines, special methods and algorithms have been developed and based on them relevant technologies are applied in order to eliminate the consequences of the accident as well.

\section{REMOTE SENSING METHOD AND SETTING OF GEODETIC MONITORING SYSTEM}

Aerospace research methods and GIS technologies are to be used in complex in organization of information-analytical system and study of factors impacting the environment during reliable organization of operation of existing and designed water pipelines, construction and operation of technical structures. However, the analysis shows that the remote sensing survey data and the methods are not used effectively in addressing of these issues.

However, in the analysis of status of the plan of the linear structures of natural-technical system, through the increase of the efficiency of utilization of aerospace information, the possibilities 
to assist in execution of appropriate actions on mitigating the impact of negative events, which already took place or to warn about different possible hazardous emergencies. However, using the aerospace information to reveal the extraordinary events makes only the part of the monitoring process. At this stage, the areas where accidents took place or are likely to occur in water supply system. But at next stage testing areas are created in those areas and measurements are carried out on the definition of the conditions of plan-altitude and straightness of line with geodetic instruments.

In the modern conception the monitoring being a system of regular survey of status of nature and man-made objects and displacement dynamics based on the given program, besides revealing of events to be occurred, in advance, also consists of forecasting of emergencies (long-term and short-term or operational), as well as management system for taking actions in connection with possible emergency situations and its development (Gojamanov, 2006) and (Gojamanov, 2009). Figure 7 shows block-diagram of geodetic monitoring system for the water supply pipelines in "Azersu” OJSC (Gurbanov, 2014).

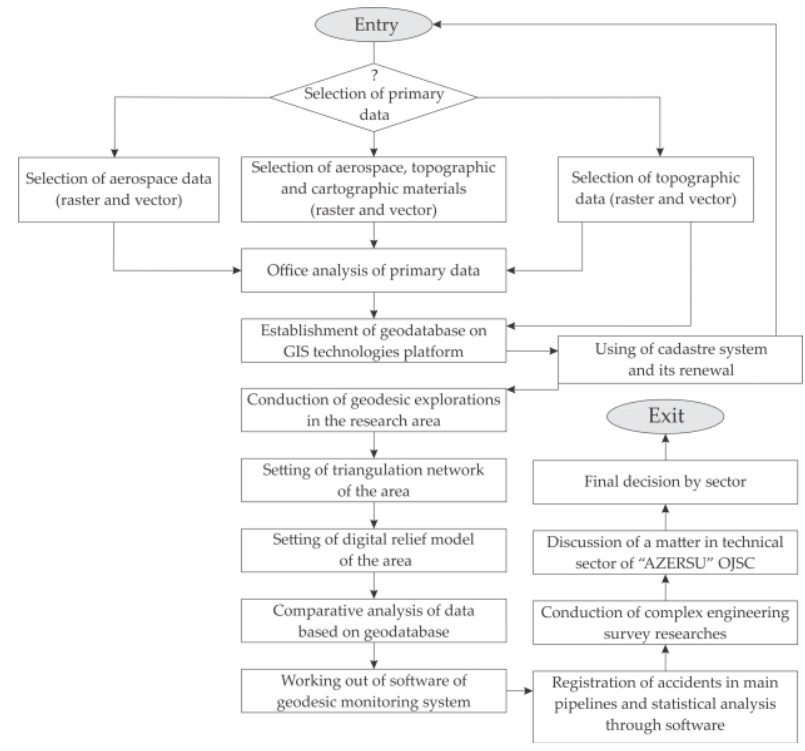

Figure 7. Geodetic block scheme of the monitoring system.

GIS is of great importance in the organization of monitoring. On its basis the information related to monitoring of pipelines is collected, processed and stored. On the other hand the information obtained from another measuring means may be entered in the GIS and at result the new aerospace-geodetic monitoring system would have been created. And it plays an important role in implementation of comprehensive evaluation of plan-altitude condition of network of the main water supply pipeline and study of impact of water supply system on environment, as well as vice versa, that is the effects of natural processes to main lines. Therefore, developing of methods and methodologies for the study of reasons of occurrence of mutual impact between main water supply pipeline of "Azersu" OJSC and environment, complex evaluation of conditions of pipelines in respect of spacetime is of great importance. The following methods and technological schemes have been used to address issues from our side:

- Thematic cartography, aerospace monitoring, analysis and tabulation methods to assess the balance of natural-terrain complexes;

- Acquisition, collection, processing and decoding by visual and automatic methods of aerospace information for assessment of the dynamics of movement of natural-terrain complexes, as well as to forecast the balance in areas of passing of pipelines;

- Creation of specific thematic maps for analysis of the naturalterrain water supply system based on processing and interpretation of results of aerospace, geodesy-cartography materials;

- Processing of space digit images with the help of ERDAS software and creation of databases along the pipeline for experimental areas;

- Transforming of cartographic materials in vector format and processing with proper applied programs (such as ArcGIS or MapInfo);

- Making the applied informative analytical GIS projects for individual areas, which require particular attention along the main pipeline;

- Probability and analytical assessment of actual and potential dangerous conditions of main pipelines.

In modern times the size, scale and speed of changes in the environment as a result of anthropogenic impacts are so great that in a single moment of time to study these changes for large areas with surface methods is practically impossible. Therefore, from modern computer technology GIS technologies, joint using of cartographic methods and distant research techniques, i.e. their integration would be the most optimal and efficient modern approach in information and cartography provision for monitoring of eco-condition of the water supply system in the space-time scale.

It should be noted that the depreciation (deterioration) of engineering constructions is directly dependent on the speed of development of natural and natural-technological processes occurred in the areas of main pipelines, natural-technical system and location of this system. In particular, at result of interaction of main pipelines with the physical and geographical environment it leads to an acceleration of process of formation and growth of wetlands, formation of karst and thermal karst, ravines and surface soil erosion, cracks and etc events, which damage of pipelines. Therefore, during the monitoring of main pipelines the state of natural and man-made elements should be evaluated in a comprehensive manner.

\section{CONCLUSION}

The following conclusions and recommendations can be made on the presented study.

1. Theoretical and experimental studies have shown that in terms of the proposed geodesic monitoring system in the event of natural and man-made, as well as the assessment of the effects of man-made events possible.

2. Geodetic measurement results and a variety of GIS spatial data management based on an integrated platform, events that may occur, depending on the interaction between the environment and the main lines of the processes may allow the establishment of evaluation and forecasting models.

3. Using of geographic information systems is very important for designing of drinking water supply and sewerage systems, and collection of date necessary for it in a common information space and more accurate implementation of the project works.

4. The study of interactions between various elements is very important in designing of water supply pipeline system, the construction and operation. In this regard, we 
prepare special methods and algorithms for assessment of geo-ecological state of natural-technical system of water supply pipelines of "Azersu"OJSC, as well as the action plan is being developed on their basis to eliminate the consequences of the accident.

5. In general, study of natural environment factors impacting the current and projected water main pipelines, the geodetic monitoring measurements for effective organization of information-analytical system, aerospace research materials and complex use of geographic information systems is more purposeful.

\section{REFERENCES}

Aliyev, E., 2011. Issues of storage, processing and compressing of remote sensing data in various widths. Materials of III scientific-practical conference on theme "Perspectives of development of Geodesy and Cartography in Azerbaijan", Baku, Azerbaijan, pp.191-199.

Gojamanov, M., Gurbanov, Ch., 2014. The features of the use of GIS technologies for monitoring of the situation of main water lines in Azerbaijan. In: The International Archives of the Photogrammetry, Remote Sensing and Spatial Information Sciences, Vol. XL-2, ISPRS Technical Commission II Symposium, 6-8 October 2014, Toronto, Canada, pp. 235-241.

Gurbanov, Ch., 2014. The creation of geodetic monitoring system in order to exploit water transmission lines. Journal of Qafqaz University - mechanical and industrial engineering, Vol. 2, number 2, pp. 142-148.

Gojamanov, M., 2006. Geodetic monitoring the location of the offshore objects. Hydrometeorology and environmental protection, Baku, Azerbaijan, No3, pp. 126-130 (in Russian).

Gojamanov, M., 2009. Geodetic maintenance and monitoring works at sea. Moscow-Baku, p.104 (in russian).

Gojamanov, M., 2014. The stability of the geodetic points in connection with geodynamic processes in Azerbaijan. ActaGeodynamica et geomaterialia, Vol.11, No.3(175), Prague, Czech, pp. 279-288. 